\title{
Lymphoepithelioma-Like Hepatocellular Carcinoma: Report of Three Cases and Review of Literature
}

\author{
Lisi Yuan ${ }^{\mathrm{a}}$, Federico Aucejo ${ }^{\mathrm{b}}$, K. V. Narayanan Menon ${ }^{\mathrm{c}}$, Xiuli Liu ${ }^{\mathrm{a}, \mathrm{d}}$
}

\begin{abstract}
Lymphoepithelioma-like carcinomas (LELCs) are carcinomas which show histologic similarities to lymphoepithelioma (AKA nasopharyngeal carcinoma) and prominently feature a lymphoid-rich stroma with tumor-infiltrating lymphocytes. LELCs have been described in a number of different organ systems, are often associated with Epstein-Barr virus (EBV) infection, and have been reported to carry favorable prognoses when compared to classic carcinomas of these organ systems. LELCs of the liver are exceedingly rare. Here, we report three cases of lymphoepithelioma-like hepatocellular carcinoma (HCC) in one female and two male patients. All three carcinomas were composed of a population of malignant cells with focal to diffuse positivity for HepPar-1, as well as a prominent lymphoplasmacytic infiltrate intimately associated with the malignant cells. In two cases investigated by immunohistochemistry, the lymphoid population contained a prominent $\mathrm{CD}^{+} \mathrm{T}$-cell population which consisted of $\mathrm{CD}^{+}$lymphocytes and $\mathrm{CD}^{+}$cytotoxic $\mathrm{T}$ cells, which also showed staining for T-cell intracellular antigen-1 (TIA-1). Chromogenic in situ hybridization for EBV-encoded RNA (EBER CISH) was negative in both the malignant cells and the lymphoid population in all three cases. Two patients who underwent surgical resection are alive without recurrence at 38 and 26 months after surgery. The third patient treated by chemoembolization died 31 months after the diagnosis.
\end{abstract}

Keywords: Lymphoepithelioma-like hepatocellular carcinoma; Lymphoid-rich stroma; EBV

\section{Introduction}

Lymphoepithelioma was first described arising in the naso-

\footnotetext{
Manuscript accepted for publication March 19, 2015

aDepartment of Anatomic Pathology, Cleveland Clinic, Cleveland, OH, USA biver Transplantation, Cleveland Clinic, Cleveland, OH, USA

${ }^{\mathrm{c}}$ Gastroenterology and Hepatology, Digestive Disease Institute, Cleveland Clinic, Cleveland, OH, USA

${ }^{\mathrm{d} C}$ Corresponding Author: Xiuli Liu, Department of Anatomic Pathology, Cleveland Clinic, 9500 Euclid Avenue/L25, Cleveland, OH 44195, USA.

Email: liux3@ccf.org
}

doi: http://dx.doi.org/10.14740/jmc2106w pharyngeal mucosa of a population of patients with a distinct geographic distribution, most prominently in patients from China and Southeast Asian nations [1]. The malignancy features a distinctive histologic pattern which includes a malignant component with squamous differentiation, as well as a characteristic lymphoid-rich stroma from which the malignancy takes its name [1]. Since its original description from the nasopharyngeal region, a series of cancers with similar histologic features and a lymphoid-rich stroma have been described in a multitude of other organs, including lung [2], bladder [3], uterine cervix [4], esophagus [5], stomach [6], and colon [7, 8]. These carcinomas have been included under the broad umbrella of lymphoepithelioma-like carcinomas (LELCs). In addition to sharing many similar histologic features with lymphoepithelioma, many of the LELCs also share an association with Epstein-Barr virus (EBV) infection [9]. Case reports and series examining the LELCs have suggested the malignancies have a better prognosis than non-LELC malignancies in the same organs [2-8].

Primary LELC of the liver is an exceedingly rare entity, and to this point very few cases have been described in the literature. In the cases that have been reported, histologic features resembling both hepatocellular carcinoma (HCC) and cholangiocarcinoma have been described $[10,11]$. Here, we report three cases of lymphoepithelioma-like HCC.

\section{Case Reports}

\section{Case 1}

An 89-year-old previously asymptomatic female presented to her primary care physician with right upper quadrant pain in July 2011. An abdominal ultrasound revealed a $5.6 \mathrm{~cm}$ lesion in the right lobe of the liver. The patient has a past medical history of hepatitis $\mathrm{C}$ viral infection diagnosed 16 years prior to presentation, breast cancer diagnosed 20 years prior to presentation, and a history of "colon polyps" 9 years prior to presentation. An abdominal MRI confirmed the presence of a heterogeneous enhancing mass in segment VIII of the liver, measuring $5.2 \mathrm{~cm}$ in greatest dimension and showing regions of central necrosis. The background liver showed features suggestive of early cirrhosis, with atrophy of the right, left and caudate lobes. The hepatic vasculature was patent, and no ad- 


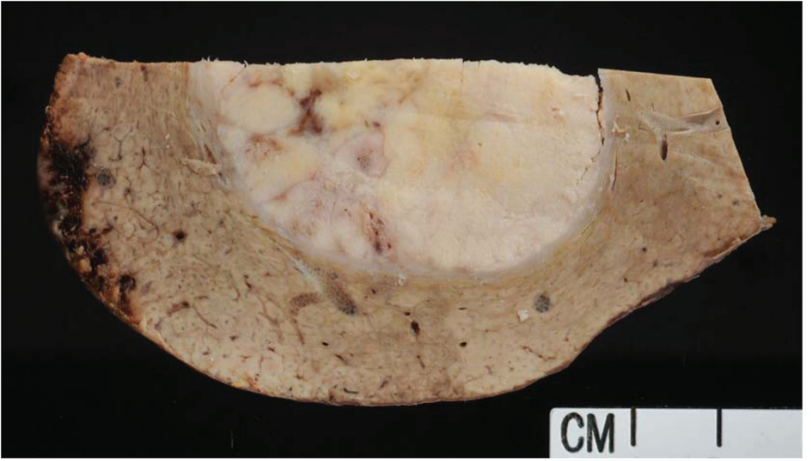

Figure 1. Gross photograph of right hepatectomy specimen from an 89 -year-old female patient with a solitary liver mass. A $5.1 \mathrm{~cm}$ wellcircumscribed, soft, white mass was present within the resection specimen.

ditional abnormalities were seen. Liver enzymes performed at the time of presentation to our institution revealed normal values for ALT (19 U/L, normal range: 0 - $45 \mathrm{U} / \mathrm{L})$, AST (36 $\mathrm{U} / \mathrm{L}$, normal range: 7 - $40 \mathrm{U} / \mathrm{L})$, alkaline phosphatase (84 U/L, normal range: 40 - $150 \mathrm{U} / \mathrm{L})$, and total bilirubin $(0.5 \mathrm{mg} / \mathrm{dL}$, normal range: 0.0 - $1.5 \mathrm{mg} / \mathrm{dL}$ ). Hepatitis $\mathrm{C}$ viral RNA quantification by PCR was positive at $297,000 \mathrm{IU} / \mathrm{mL}$. The patient's serum alpha fetoprotein (AFP) level was markedly elevated at $1,054.0 \mathrm{ng} / \mathrm{mL}$ (normal range: $0-11 \mathrm{ng} / \mathrm{mL}$ ). Based on the findings, the decision was made to proceed with surgical resection. Prior to the procedure, the patient underwent embolization of the right portal vein, which was followed by a right hepatectomy during which a $410 \mathrm{~g}$ segment of the patient's right liver lobe was excised.

Upon gross examination of the resection specimen, a single mass was identified, measuring $5.1 \mathrm{~cm}$ in greatest dimension (Fig. 1). The mass was well-circumscribed, soft, and white, with a bulging cut surface. Necrosis comprised approximately $20 \%$ of the mass (not photographed). Wire coils and rubbery beads, relics of the preoperative embolization, were identified in the vasculature (not photographed). A hemorrhagic area was noted near the tumor, likely secondary to embolization of the right portal vein. No additional masses were identified. The background liver showed no evidence of cirrhosis on macroscopic examination (Fig. 1).

On histologic sections, the tumor was composed of markedly pleomorphic cells with eosinophilic cytoplasm and a high nuclear-cytoplasmic ratio. In addition, a dense lymphoid stroma was associated with the carcinoma cells, and was composed of a mixture of mature lymphocytes and plasma cells. The lymphoid infiltrate was present both at the periphery of the tumor, as well as within the tumor, intimately intermixed with the carcinoma cells (Fig. 2). There was no evidence of large vein invasion but microscopic lymphovascular invasion was identified. No conventional HCC component was identified. The background liver showed a chronic hepatitis of mild activity with portal and periportal fibrosis (Batts and Ludwig: grade $2 / 4$, stage 1-2/4) without evidence of bridging fibrosis or cirrhosis. There was no evidence of iron deposition on Perl's Prussian blue iron stain or alpha 1 antitrypsin inclusion on periodic acid-Schiff (PAS) stain with diastase digestion. Immunohistochemical studies through use of a battery of antibod-
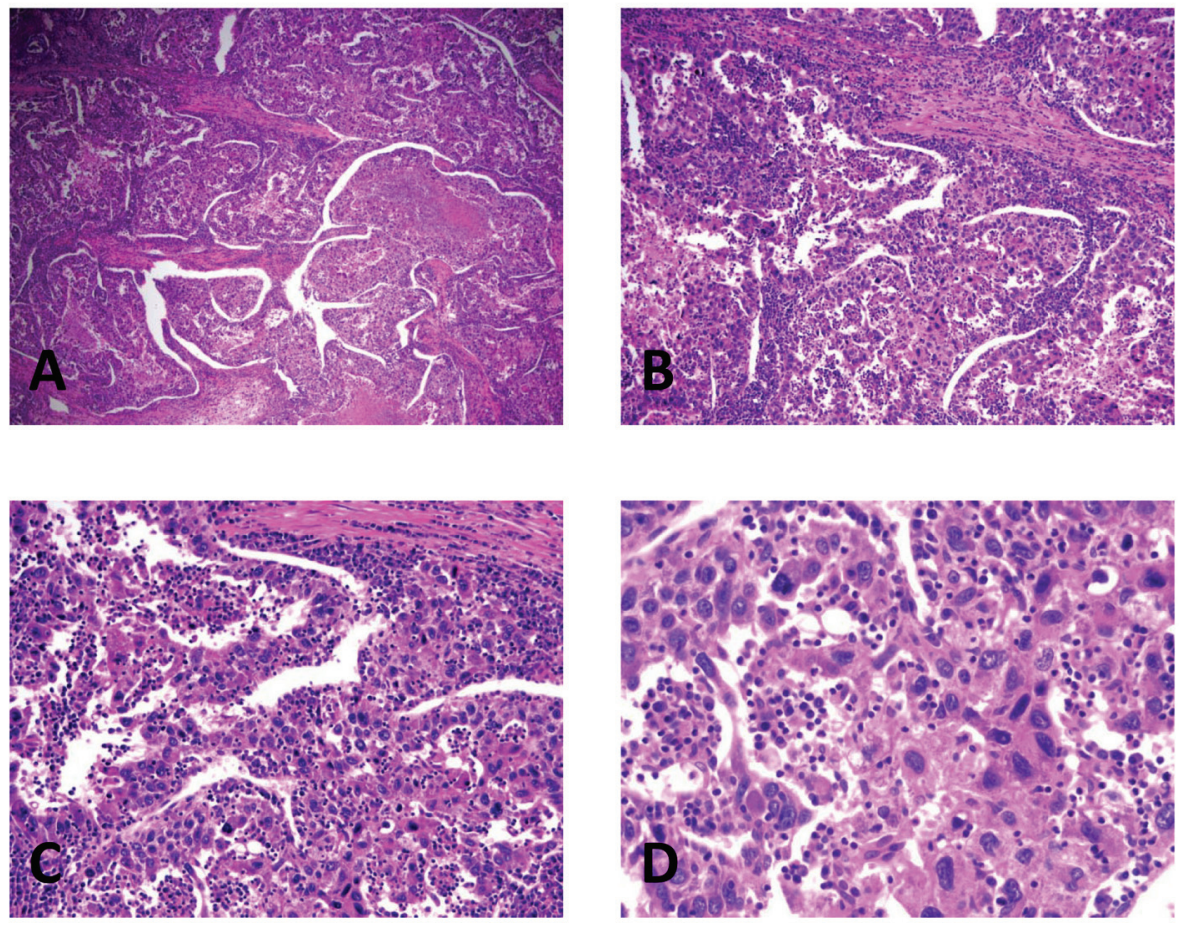

Figure 2. Histopathology of lymphoepithelioma-like hepatocellular carcinoma in the right lobectomy specimen, illustrating the pleomorphic malignant cells and the intimately associated lymphoplasmacytic infiltrate. (A) H\&E, $\times 40$. (B) H\&E, × 100. (C) H\&E, $\times$ 200. (D) H\&E, $\times 400$. 

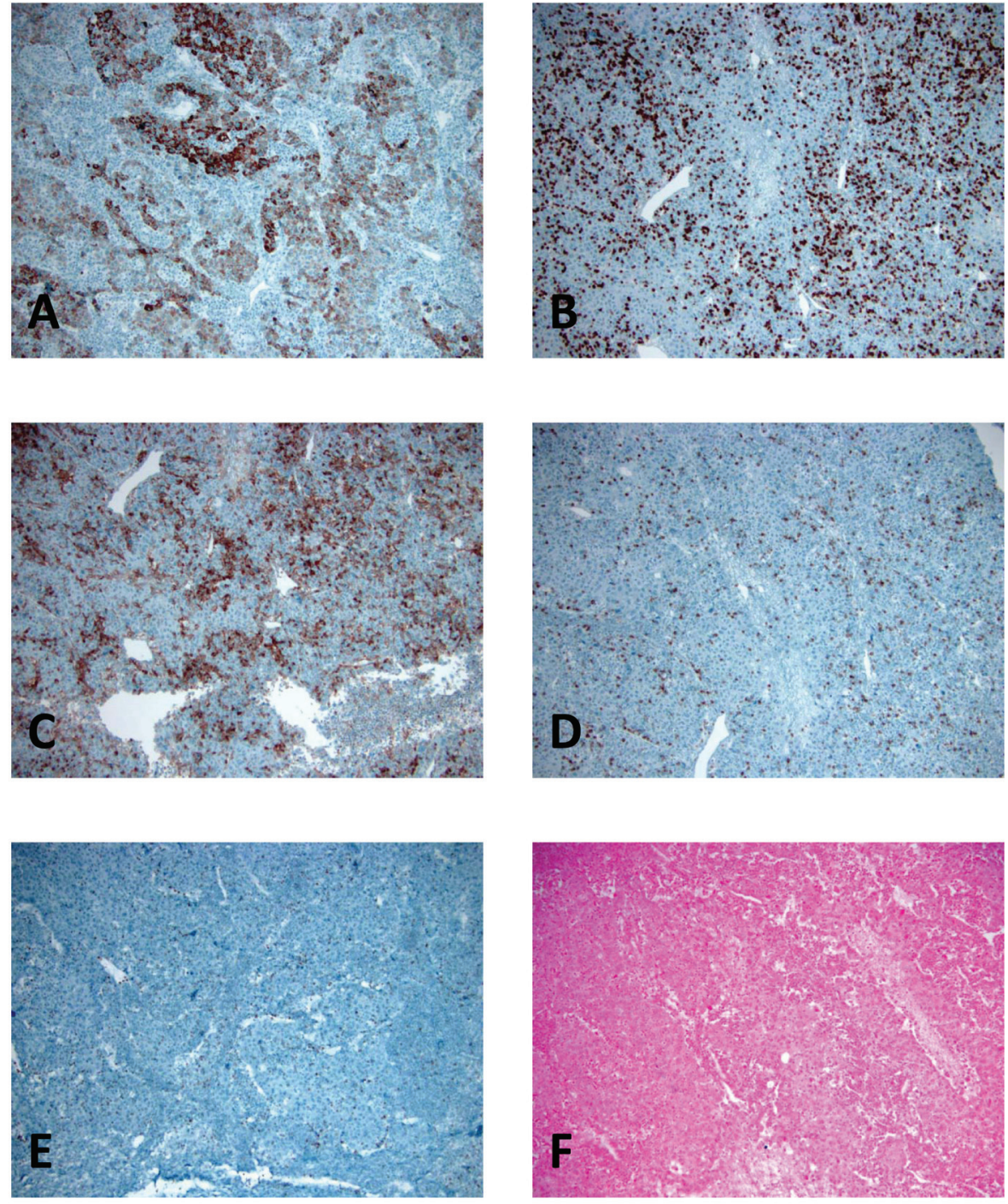

Figure 3. Immunophenotype of lymphoepithelioma-like hepatocellular carcinoma in the resection specimen, revealing the hepatocellular origin of the malignant cells and a prominent cytotoxic T-cell population, without evidence of Epstein-Barr virus infection. (A) Hep-Par-1, × 100. (B) CD3, × 100. (C) CD4, × 100. (D) CD8, × 100. (E) TIA-1, × 100. (F) EBER chromogenic in situ hybridization, $\times 100$.

ies including hepatocyte (HepPar-1, OCH1E5, 1:800, DAKO, Carpinteria, CA); CD3 (2GV6, prediluted, Ventana Medical System, Inc., Tucson, AZ); CD20 (L26, 1:25, DAKO, Carpinteria, CA); CD4 (1FC, 1:10, Novocastra, Newcastle upon Tyne, UK); CD8 (1A5, 1:10, Biogenex, Fremont, CA); TIA-1 (TIA1, prediluted, Biocare Medical, LLC, Concord, CA); CD138 (BC/B-B4, 1:200, Biocare Medical, LLC, Concord, CA), and chromogenic in situ hybridization (CISH) for EBV-encoded RNA (EBER CISH, ISH I-VIEW Blue Plus kit, Ventana Medical System, Inc., Tucson, AZ), as well as kappa and lambda immunoglobulin light chains (kappa light chain messenger RNA and lambda light chain messenger RNA, performed according to the manufacturer's instructions, Ventana Medical System, Inc., Tucson, AZ). The malignant cells showed focal positivity for HepPar-1, supporting their hepatocellular origin. The lymphoid population showed a subpopulation of CD20 ${ }^{+}$
$\mathrm{B}$ cells, as well as a prominent $\mathrm{CD} 3^{+} \mathrm{T}$-cell population. The T-cell population consisted of both $\mathrm{CD}^{+} \mathrm{CD}^{+}$lymphocytes and $\mathrm{CD}^{+} \mathrm{CD}^{+}$cytotoxic $\mathrm{T}$ cells which also showed staining for T-cell intracellular antigen-1 (TIA-1). The cytotoxic T cells predominantly consisted of the intratumoral cytotoxic lymphocytes located within the malignancy itself (Fig. 3). A CD138 stain highlighted the plasma cell component of the lymphoid infiltrate; however, the plasma cells were polyclonal on kappa and lambda light chain CISH. Chromogenic in situ hybridization of EBV-encoded RNA was negative in both the lymphoid cells and the malignant cells. Based on these findings, a final diagnosis of "HCC with a dense lymphoid stroma (hepatocellular lymphoepithelioma-like carcinoma), stage II (according to AJCC cancer staging manual, the 7th edition)" was considered. The patient is alive without recurrence at 38 months after surgery. 


\section{Case 2}

A 64-year-old male with a history of hepatitis B infection of approximately 30 years was noted to have a $2 \mathrm{~cm}$ mass in the left lobe of the liver with diffuse fatty changes in the rest of the liver during follow-up imaging for esophageal cancer. A liver biopsy 10 years ago showed chronic hepatitis with moderate lobular activity and mild periportal fibrosis. One year prior to presentation the patient had undergone an esophagectomy for intramucosal adenocarcinoma of the esophagus. Liver function tests performed at the time revealed normal values for ALT (18 $\mathrm{U} / \mathrm{L}$, normal range: 0 - $45 \mathrm{U} / \mathrm{L})$, AST $(21 \mathrm{U} / \mathrm{L}$, normal range: 7 - $40 \mathrm{U} / \mathrm{L})$, alkaline phosphatase $(81 \mathrm{U} / \mathrm{L}$, normal range: 40 - $150 \mathrm{U} / \mathrm{L})$, and total bilirubin $(0.3 \mathrm{mg} / \mathrm{dL}$, normal range: 0.0 $1.5 \mathrm{mg} / \mathrm{dL}$ ). Serology test performed at the time showed negative hepatitis B viral DNA, negative Hep B surface antigen, negative HBV E antigen, negative HBV E antibody, positive HBV surface antibody and positive HBV core antibody. The patient's serum AFP level was elevated at $305.5 \mathrm{ng} / \mathrm{mL}$ (normal range: 0 - $11 \mathrm{ng} / \mathrm{mL}$ ). No additional serum tumor markers were performed. This liver lesion was biopsied and showed HCC with a rich lymphoid stroma. Based on these findings, the patient underwent a left lobectomy.

Upon gross examination of the resection specimen (measuring $11.7 \times 11.1 \times 3.0 \mathrm{~cm}$ and weighing $170 \mathrm{~g}$ ), a single mass was identified, measuring $3.7 \mathrm{~cm}$ in greatest dimension. The mass was well-circumscribed, soft, and white. A hemorrhagic area $(0.8 \times 0.7 \mathrm{~cm})$ was noted near the tumor. No additional masses were identified. The background liver showed no evidence of cirrhosis on macroscopic examination.

On histologic section, the tumor was composed of markedly pleomorphic, poorly differentiated carcinoma cells with eosinophilic cytoplasm and a high nuclear-cytoplasmic ratio. No conventional HCC component was identified. In addition, a dense lymphoid stroma was associated with the carcinoma cells, and was composed of a mixture of mature lymphocytes and plasma cells. The lymphoid infiltrate was present both at the periphery of the tumor, as well as within the tumor, intimately intermixed with the carcinoma cells. The background liver showed a chronic hepatitis of mild activity with minimal portal fibrosis without evidence of bridging fibrosis or cirrhosis. There was no evidence of iron deposition on Perl's Prussian blue iron stain or alpha 1 antitrypsin inclusion on PAS stain with diastase digestion.

Immunohistochemical studies (performed on the liver mass biopsy specimen) revealed that the malignant cells showed focal positivity for HepPar-1 supporting their hepatocellular origin. The tumor demonstrated membranous and canalicular staining pattern for polyclonal CEA, but was negative for MOC31 and CK7, in line with its hepatocellular origin. The lymphoid population showed a subpopulation of CD20 ${ }^{+}$ $\mathrm{B}$ cells, as well as a prominent $\mathrm{CD}^{+}{ }^{+} \mathrm{T}-$-cell population. The T-cell population consisted of both $\mathrm{CD} 3^{+} \mathrm{CD} 4^{+}$lymphocytes and $\mathrm{CD}^{+} \mathrm{CD}^{+}$cytotoxic $\mathrm{T}$ cells which also showed staining for TIA-1. The cytotoxic $T$ cells predominantly consisted of the intratumoral cytotoxic lymphocytes located within the malignancy itself. The plasma cells were polyclonal on kappa and lambda light chain CISH. Chromogenic in situ hybridization of EBV-encoded RNA was negative both in the lymphoid cells and the malignant cells. Based on these findings in the biopsy and resection specimens, a diagnosis of "HCC with a dense lymphoid stroma (lymphoepithelioma-like HCC), stage I (according to AJCC cancer staging manual, the 7th edition)" was considered. The patient received no further HCC-specific treatment and is alive without recurrence 26 months after surgery.

\section{Case 3}

A 60-year-old male with a history of hepatitis $\mathrm{C}$ infection of approximately 20 years and was noted to have an elevated AFP level at $45.1 \mathrm{ng} / \mathrm{mL}$. An abdominal MRI study revealed two T2 intense liver lesions $(5.6 \mathrm{~cm}$ and $1.6 \mathrm{~cm})$ in the right lobe of the liver. There were no accompanying symptoms such as jaundice, ascites, or GI bleeding. There was no documented history of alcohol abuse. The patient has a past medical history significant for chronic obstructive pulmonary disease of 5-year duration and cholelithiasis status post cholecystectomy 2 years ago. Liver tests performed at the time revealed a normal value for ALT ( $45 \mathrm{U} / \mathrm{L}$, normal range: 0 - $45 \mathrm{U} / \mathrm{L}$ ), a slight increase in AST (62 U/L, normal range: 7 - $40 \mathrm{U} / \mathrm{L}$ ), a slight increase in alkaline phosphatase (159 U/L, normal range: 40 - $150 \mathrm{U} / \mathrm{L})$, normal value for total bilirubin $(0.6 \mathrm{mg} / \mathrm{dL}$, normal range: 0.0 - $1.5 \mathrm{mg} / \mathrm{dL})$, a decrease in total protein $(5.3 \mathrm{ng} / \mathrm{dL}$, normal range: $6.0-8.4 \mathrm{~g} / \mathrm{dL})$ and albumin $(3.1 \mathrm{~g} / \mathrm{dL}$, normal range: 3.5 $-5.0 \mathrm{ng} / \mathrm{dL}$ ). The patient had normal serum alpha 1 antitrypsin level at $187 \mathrm{mg} / \mathrm{dL}$ (normal range: $100-220 \mathrm{mg} / \mathrm{dL}$ ). Hepatitis C viral RNA quantification by PCR was positive, at 426,000 $\mathrm{IU} / \mathrm{mL}$. Needle biopsy of the larger liver mass was performed.

On histologic sections of the liver mass biopsy, the tumor was composed of markedly pleomorphic, poorly differentiated carcinoma cells with eosinophilic cytoplasm and a high nuclear-cytoplasmic ratio. In addition, a dense lymphoid stroma was associated with the carcinoma cells, and was composed of a mixture of mature lymphocytes and plasma cells. The lymphoid infiltrate was present both at the periphery of the tumor, as well as within the tumor, intimately intermixed with the carcinoma cells. There was no non-neoplastic liver parenchyma present for the evaluation of background liver disease. Immunohistochemical studies showed that the malignant cells were positive for HepPar-1, supporting their hepatocellular origin. The tumor cells also demonstrated membranous and canalicular staining pattern for polyclonal CEA. The plasma cells were polyclonal on kappa and lambda light chain CISH. Based on the overall findings, the liver mass was diagnosed as $\mathrm{HCC}$ with a rich lymphoid stroma.

Because of the patient's severe COPD and the HCC being beyond Milan criteria, the decision was made to proceed with locoregional therapy with chemoembolization. The patient died of disease at 31 months after the diagnosis of HCC despite the treatment.

\section{Discussion}

The clinicopathologic features of rare HCCs with marked lym- 


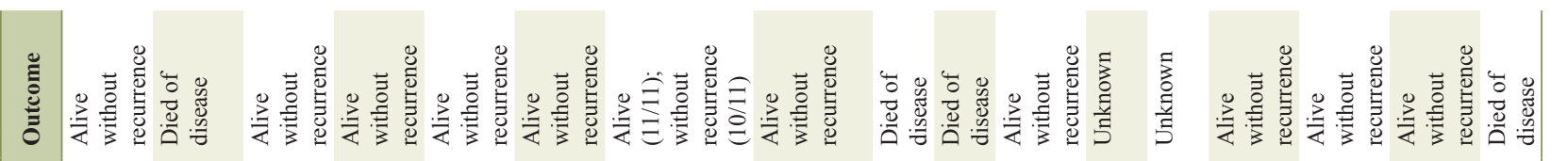

$4 !+1 !+1111+11$

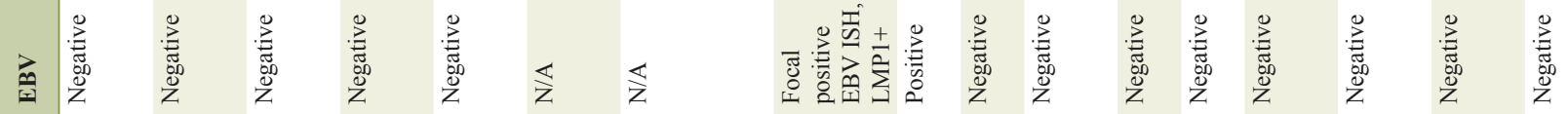

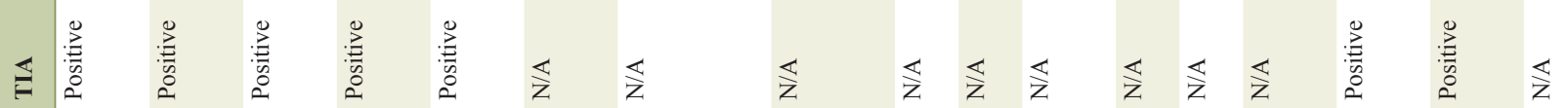

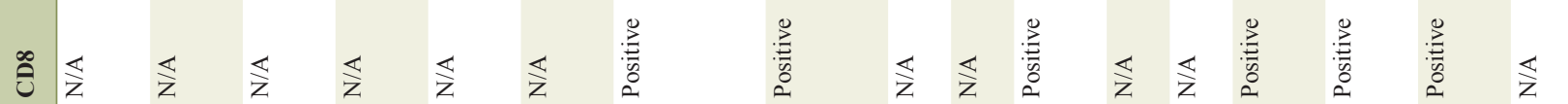

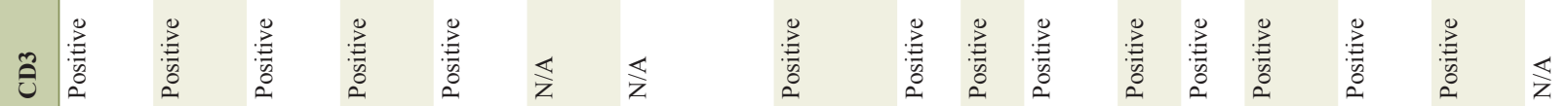

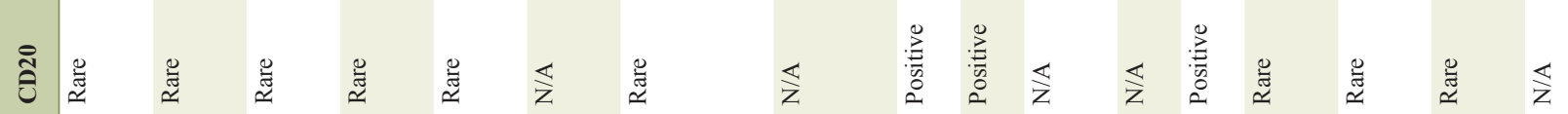

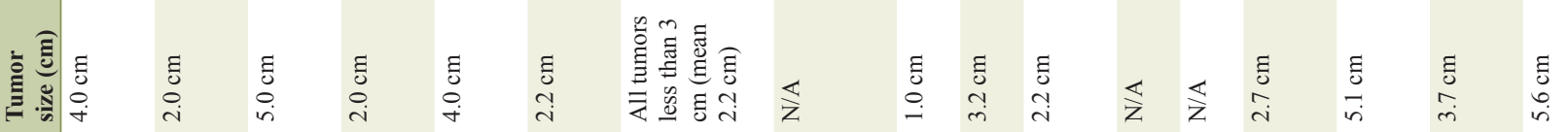

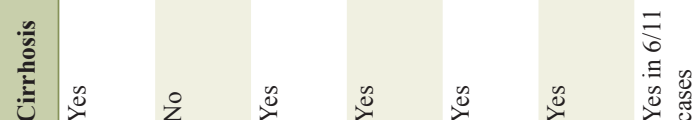

ญัँ

$\Sigma \Sigma \Sigma \Sigma \Sigma$ I $\Sigma$

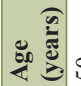

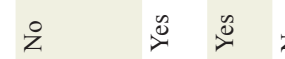

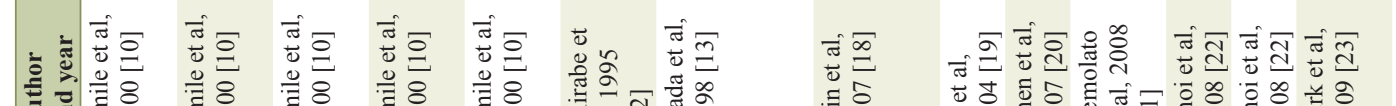

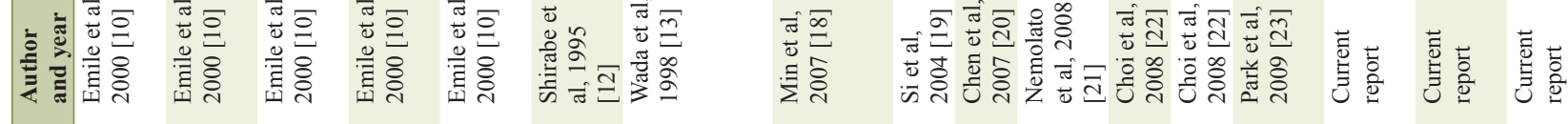

站

in $\quad \stackrel{5}{i}$
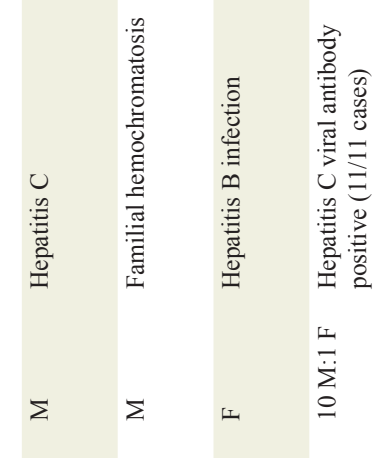

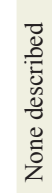
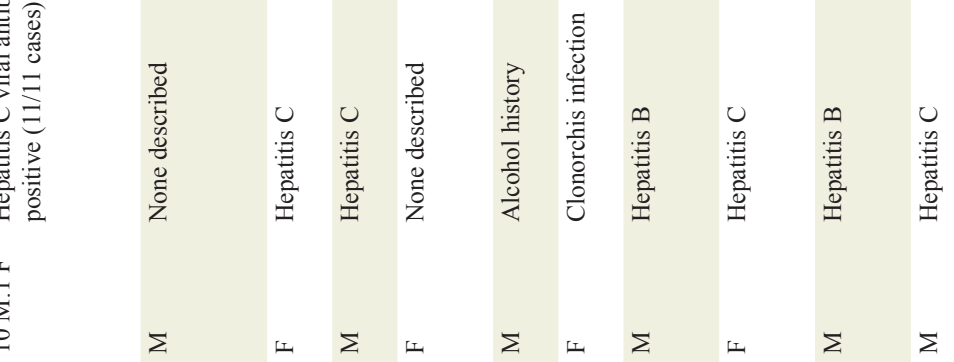

$\Sigma$

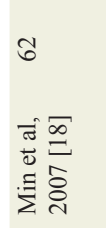

$\left(\frac{10}{10}\right.$

$\stackrel{\infty}{\sim} \stackrel{4}{4}$

$\tilde{4} \tilde{n}^{3}$

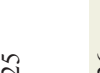

ì 
phocytic infiltration have been documented in case reports and series in Japan $[12,13]$, the largest of which comprised 11 cases examined by Wada et al in 1998 [13]. In 2000, Emile et al published a small case series that examined five cases of what the author termed "HCCs with lymphoid stroma", or hepatocellular CLS, likely corresponding to the cases of HCC with marked lymphocytic infiltration previously described by the Japanese publications [10]. The following year, Szekely argued that the entities described by Emile were indistinguishable from the LELCs described in multiple other organ systems, and advocated terming the liver malignancies as LELCs in order to emphasize their similarities to those previously described [14]. In the intervening years, additional case reports have been published detailing findings consistent with those initially described by Emile et al [10]. However, lymphoepithelioma-like HCCs remain a rare entity. Our current report adds three additional cases to the existing literature. It should be noted that cases of cholangiocarcinoma with components of LELC have also been documented arising in the liver [11, 15-18]; these lymphoepithelioma-like cholangiocarcinomas were not included in this review. The detailed literature review of lymphoepitheliomalike HCC is summarized in Table 1 [10, 12, 13, 18-23].

The three patients described in our series had documented hepatitis $\mathrm{C}$ (two cases) and hepatitis $\mathrm{B}$ viral infection (one case), a finding which is consistent with the cases previously described in literature. None of our cases had evidence of cirrhosis. Of the 27 cases of lymphoepithelioma-like HCC described in literature, 21 patients $(78 \%)$ demonstrated seropositivity for either hepatitis $\mathrm{B}$, hepatitis $\mathrm{C}$, or in one case, hepatitis $\mathrm{B}$ and $\mathrm{C}$ viral infection (Table 1). In addition, four other cases of LELC arose in patients with a documented history of underlying liver disease, including hereditary hemochromatosis [10], previous HCC status post right lobectomy [10], alcohol use [22] and Clonorchis infection [22]. Only two cases of LELC have been documented as arising in the absence of hepatitis viral infection or underlying liver disease $[18,21]$. However, despite the presence of underlying liver injury in 25 of the 27 documented cases of LELC (93\% of cases), $48 \%$ of reported cases (13/27), including all three cases described in this paper, lacked either gross, histologic, or clinical evidence of cirrhosis (Table 1). Whether underlying liver disease, viral or otherwise, can be considered an etiologic factor for LELCs of the liver has yet to be determined. The absence of cirrhosis in 13 of the 27 (48\%) described cases, however, demonstrates that LELCs have the potential to develop in non-cirrhotic livers, with or without a documented underlying liver disease.

EBV infection has long been acknowledged as playing a role in the pathogenesis of nasopharyngeal carcinoma, and EBER CISH performed on these malignancies show a characteristic strong positivity in nearly all of the malignant cells [1]. The association of EBV with LELCs of various organ systems, however, is less distinct. In a literature review performed by Iezonni and colleagues in 1994, LELCs of the salivary gland, thymus, lung and stomach demonstrated positivity for EBV. In contrast, LELCs of the uterine cervix, bladder, skin and breast were negative for EBV [9]. Subsequent case reports which described LELCs in additional organ systems have demonstrated EBV positivity in LELCs of the esophagus, colon and rectum $[5,7,8]$. Of the 27 cases of liver LELC reviewed in Table 1,
15 cases were evaluated for the presence of EBV. Thirteen of the 15 cases $(87 \%)$ were negative for EBV [10, 18-23]. Only two cases demonstrated EBV positivity within lymphoepithelioma-like HCC $[18,19]$. Of the two EBV-positive cases, one showed focal differentiation of cholangiocarcinoma [18]; EBV positivity has previously been demonstrated in lymphoepithelioma-like cholangiocarcinomas [11, 15-17]. The ultimate role of EBV in the pathogenicity of these and other LELCs remains unclear, and the fact that the majority of lymphoepitheliomalike HCCs reported in the literature arose in its absence indicate it is not the major etiologic factor in their development [9].

On review of LELCs of various organ systems, it has become generally accepted that LELCs carry a better prognosis than comparable malignancies in the same organ systems. In the lung [2], stomach [6], uterine cervix [4], and bladder [3], studies have reported favorable prognoses when compared to non-LELC malignancies, and this finding has been described in HCCs as well $[12,24]$. As the number of reported lymphoepithelioma-like HCCs remains small, the evaluation of prognostic implications is limited. Of the 27 cases of LELC including 24 published cases and three cases described in this report, 25 had follow-up data available for review. With follow-up periods ranging in length from 4.5 months to 8 years, including one case with an unknown length of follow-up, 21 of the 25 patients $(84 \%)$ were alive without recurrence of disease, while one $(4 \%)$ was alive with recurrence (Table 1$)$. Of the four cases where the patient died of their disease, one developed multiple recurrences following liver transplant and died shortly thereafter [19]; one developed metastatic disease to parapancreatic and para-aortic lymph nodes, progressed to hemoperitoneum, and died 21 months following right lobectomy [20]; one had a previously documented history of HCC and had undergone right hepatectomy 2 years prior to liver transplant, died at 7.7 years after liver transplantation [10]; and one had progressive disease and died 31 months following chemoembolization treatment alone. Among the four patients who died of disease, one had EBV-positive LELC which had metastasized to a portal lymph node and this patient developed recurrence and died shortly after liver transplant. It remains to be determined whether the immunosuppressant status post-transplantation accelerates the recurrence of the disease. In addition, of the four patients who died of disease, one had tumor beyond Milan criteria at the time of diagnosis (case 27, our current report) and received chemoembolization treatment only. It has been suggested that the accumulation of inflammatory cells at the site of LELCs may contribute to their observed favorable prognoses, representing a localized immune response to the malignant cells [2, $10,25]$. In studies that have characterized the lymphoid component of LELCs in various organ systems, a prominent $\mathrm{CD}^{+}$ T-cell population has been described, which has been observed to be associated with co-expression of cytotoxic markers including CD8 and TIA-1 [2, 4, 5, 13, 19-20, 23]; these findings were also observed in the cases described in our report.

In summary, we have reported three cases of lymphoepithelioma-like HCC arising in patients with chronic, non-cirrhotic, viral hepatitis. Given the small number of these malignancies that have been described, many aspects of these tumors, including etiologic agents, remain unknown. Based on previously described cases of hepatocellular LELCs, the malignan- 
cies appear to carry a favorable prognosis when compared to classical HCCs, and therefore warrant recognition as a unique entity distinct from conventional HCC. However, further conclusions on the pathogenesis and prognosis of these malignancies would require additional studies in larger cohorts.

\section{Financial Support}

None.

\section{Conflicts of Interest}

None.

\section{References}

1. Barnes L EJ, Reichart P, Sidransky D. World Health Organization Classification of Tumours: Pathology and Genetics of Head and Neck Tumours. Lyon, France: IARC Press; 2005.

2. Ho JC, Wong MP, Lam WK. Lymphoepithelioma-like carcinoma of the lung. Respirology. 2006;11(5):539-545.

3. Porcaro AB, Gilioli E, Migliorini F, Antoniolli SZ, Iannucci A, Comunale L. Primary lymphoepithelioma-like carcinoma of the urinary bladder: report of one case with review and update of the literature after a pooled analysis of 43 patients. Int Urol Nephrol. 2003;35(1):99-106.

4. Skinner NE, Horowitz RI, Majmudar B. Lymphoepithelioma-like carcinoma of the uterine cervix. South Med J. 2000;93(10):1024-1027.

5. Chen PC, Pan CC, Hsu WH, Ka HJ, Yang AH. EpsteinBarr virus-associated lymphoepithelioma-like carcinoma of the esophagus. Hum Pathol. 2003;34(4):407-411.

6. Herath $\mathrm{CH}$, Chetty R. Epstein-Barr virus-associated lymphoepithelioma-like gastric carcinoma. Arch Pathol Lab Med. 2008;132(4):706-709.

7. Kon S, Kasai K, Tsuzuki N, Nishibe M, Kitagawa T, Nishibe T, Sato N. Lymphoepithelioma-like carcinoma of rectum: possible relation with EBV. Pathol Res Pract. 2001;197(8):577-582.

8. Samaha S, Tawfik O, Horvat R, Bhatia P. Lymphoepithelioma-like carcinoma of the colon: report of a case with histologic, immunohistochemical, and molecular studies for Epstein-Barr virus. Dis Colon Rectum. 1998;41(7):925-928.

9. Iezzoni JC, Gaffey MJ, Weiss LM. The role of EpsteinBarr virus in lymphoepithelioma-like carcinomas. Am J Clin Pathol. 1995;103(3):308-315.

10. Emile JF, Adam R, Sebagh M, Marchadier E, Falissard B, Dussaix E, Bismuth H, et al. Hepatocellular carcinoma with lymphoid stroma: a tumour with good prognosis after liver transplantation. Histopathology. 2000;37(6):523529.
11. Jeng YM, Chen CL, Hsu HC. Lymphoepithelioma-like cholangiocarcinoma: an Epstein-Barr virus-associated tumor. Am J Surg Pathol. 2001;25(4):516-520.

12. Shirabe K, Matsumata T, Maeda T, Sadanaga N, Kuwano $\mathrm{H}$, Sugimachi K. A long-term surviving patient with hepatocellular carcinoma including lymphocytes infiltration--a clinicopathological study. Hepatogastroenterology. 1995;42(6):996-1001.

13. Wada Y, Nakashima O, Kutami R, Yamamoto O, Kojiro M. Clinicopathological study on hepatocellular carcinoma with lymphocytic infiltration. Hepatology. 1998;27(2):407-414.

14. Szekely E. Hepatocellular carcinoma with lymphoid stroma: 'lymphoepithelioma-like carcinoma'? Histopathology. 2001;39(5):540.

15. Henderson-Jackson E, Nasir NA, Hakam A, Nasir A, Coppola D. Primary mixed lymphoepithelioma-like carcinoma and intra-hepatic cholangiocarcinoma: a case report and review of literature. Int J Clin Exp Pathol. 2010;3(7):736-741.

16. Hsu HC, Chen CC, Huang GT, Lee PH. Clonal EpsteinBarr virus associated cholangiocarcinoma with lymphoepithelioma-like component. Hum Pathol. 1996;27(8):848850 .

17. Huang Y, Tsung JS, Lin CW, Cheng TY. Intrahepatic cholangiocarcinoma with lymphoepithelioma-like carcinoma component. Ann Clin Lab Sci. 2004;34(4):476-480.

18. Min HS, Shin E, Jang JJ. [Carcinoma with predominant lymphoid stroma in hepatobiliary system--report of 2 cases]. Korean J Hepatol. 2007;13(2):222-227.

19. Si MW, Thorson JA, Lauwers GY, DalCin P, Furman J. Hepatocellular lymphoepithelioma-like carcinoma associated with epstein barr virus: a hitherto unrecognized entity. Diagn Mol Pathol. 2004;13(3):183-189.

20. Chen CJ, Jeng LB, Huang SF. Lymphoepitheliomalike hepatocellular carcinoma. Chang Gung Med J. 2007;30(2):172-177.

21. Nemolato S, Fanni D, Naccarato AG, Ravarino A, Bevilacqua G, Faa G. Lymphoepitelioma-like hepatocellular carcinoma: a case report and a review of the literature. World J Gastroenterol. 2008;14(29):4694-4696.

22. Choi HJ, Choi JH. [Hepatocellular carcinoma with lymphoid stroma: report of two cases]. Korean J Hepatol. 2008;14(3):394-398.

23. Park HS, Jang KY, Kim YK, Cho BH, Moon WS. Hepatocellular carcinoma with massive lymphoid infiltration: a regressing phenomenon? Pathol Res Pract. 2009;205(9):648-652.

24. Ng IO, Lai EC, Fan ST, Ng MM, So MK. Prognostic significance of pathologic features of hepatocellular carcinoma. A multivariate analysis of 278 patients. Cancer. 1995;76(12):2443-2448.

25. Amin MB, Ro JY, Lee KM, Ordonez NG, Dinney CP, Gulley ML, Ayala AG. Lymphoepithelioma-like carcinoma of the urinary bladder. Am J Surg Pathol. 1994;18(5):466473. 